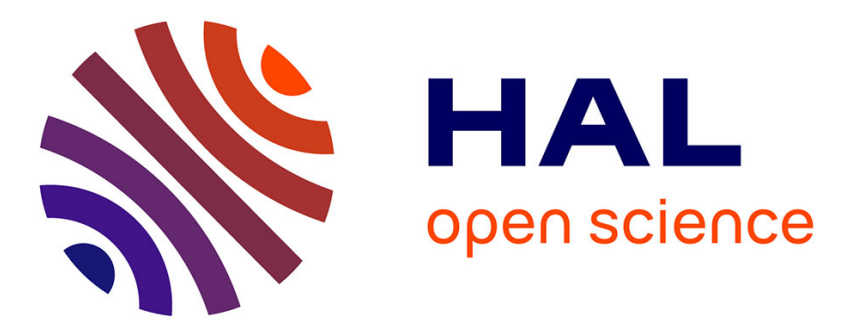

\title{
Brain metastases in endometrial cancer: a systematic review of the surgical prognostic factors
}

Nathan Beucler, Aurore Sellier, Cédric Bernard, Christophe Joubert, Nicolas

Desse, Arnaud Dagain

\section{- To cite this version:}

Nathan Beucler, Aurore Sellier, Cédric Bernard, Christophe Joubert, Nicolas Desse, et al.. Brain metastases in endometrial cancer: a systematic review of the surgical prognostic factors. European Journal of Obstetrics \& Gynecology and Reproductive Biology, 2021, 258, pp.240-252. 10.1016/j.ejogrb.2021.01.007 . hal-03266673

\section{HAL Id: hal-03266673 \\ https://hal.sorbonne-universite.fr/hal-03266673}

Submitted on 22 Jun 2021

HAL is a multi-disciplinary open access archive for the deposit and dissemination of scientific research documents, whether they are published or not. The documents may come from teaching and research institutions in France or abroad, or from public or private research centers.
L'archive ouverte pluridisciplinaire HAL, est destinée au dépôt et à la diffusion de documents scientifiques de niveau recherche, publiés ou non, émanant des établissements d'enseignement et de recherche français ou étrangers, des laboratoires publics ou privés. 


\title{
Brain metastases in endometrial cancer:
}

\section{a systematic review of the surgical prognostic factors}

\author{
Nathan BEUCLER ${ }^{* 1,2,3}$, Aurore SELLIER ${ }^{1,2}$, Cédric BERNARD ${ }^{1}$, Christophe \\ JOUBERT $^{1}$, Nicolas DESSE ${ }^{1}$, Arnaud DAGAIN ${ }^{1,4}$
}

*Corresponding author: nathan.beucler@ neurochirurgie.fr - +0033649149620 -

ORCID 0000-0003-3047-4234

1 Neurosurgery department, Sainte-Anne Military Teaching Hospital, 2 boulevard SainteAnne, 83800 Toulon Cedex 9, France

2 Ecole du Val-de-Grâce, French Military Health Service Academy, 1 place Alphonse

Laveran, 75230 Paris Cedex 5, France

3 Neuro-oncology department, Pitié-Salpêtrière University Hospital, AP-HP, Sorbonne

University Medical School, 75013 Paris, France

4 Val-de-Grâce Military Academy, 1 place Alphonse Laveran, 75230 Paris Cedex 5, France 


\section{ABSTRACT}

Context: although endometrial cancer is the fourth most common malignancy in women, dissemination to the brain is an exceptional event in the course of the disease. The aim of this review is to determine the important surgical prognostic factors for patients with endometrial cancer metastatic to the brain.

Materials and methods: report of two cases. Medline database was used to conduct a systematic literature review from inception to December 2020 looking for Englishlanguage articles focused on brain metastases from endometrial cancer

Results: the research yielded 108 articles, among which 23 articles were retained for a total of 87 patients. Mean age was 60 years-old \pm 11 at the time of diagnosis of endometrial cancer, and most of the tumors were aggressive (grade 3 ) with an advanced-stage disease (FIGO III, IV). At the time of diagnosis of cerebral disease, a single brain metastasis ( $\mathrm{p}<$ $0.0001)$ and no extra-cerebra metastatic site $(\mathrm{p}=0.0011)$ were significant good prognostic factors for the median overall survival. Surgical excision of brain metastasis followed by radiotherapy provided the longest median overall survival compared to radiotherapy and/or chemotherapy, and surgery alone (respectively $32,5.4$ and 4.8 months, $\mathrm{p}<0.0001$ ). An age of 60-year-old or less was not associated with a better prognosis.

Conclusion: This review confirms that surgical excision followed by radiotherapy is a reliable option in patients with a single brain metastasis from endometrial cancer and no extra-cerebral metastatic site. This work could help to adapt the Graded Prognostic Assessment for brain metastases in endometrial cancer. 


\section{MANUSCRIPT}

\section{INTRODUCTION}

With an incidence of 88068 in 2013 in the European Union (7\% of all new cancers diagnosed in women), endometrial cancer (EC) is the fourth most common malignancy in women, the most frequent gynaecological tumor in developed countries and is ranked seventh in terms of mortality. [1-3] Mean age at diagnosis is 60 years old and it is revealed in $75 \%$ of the cases at an early stage (FIGO I-II) thanks to post-menopause abnormal uterine bleeding; [1,4] at this stage, the 5-year overall survival ranges from 74-91\%. The 5-year overall survival falls to 57- 66\% in FIGO stage III, and 20-26\% in FIGO stage IV. [1,5] Consequently, EC carries a rather good prognosis which is highly correlated with surgical staging including the tumor's size, the extent of myometrial invasion and lymphovascular space involvement, histological type and grade, the presence of local and distant metastases, and the patient's age. Typical metastatic sites include the pelvis, the

peritoneum, the lungs and the bones. Exceptionally, the course of the disease is impeded by one or multiple cerebral metastases (0.3-0.9\% of the cases) which are associated with a more dismal prognostic. [6-11] To our knowledge, there is only one other contemporary review which included all subtypes of uterus tumors. This review aims to determine the optimal surgical strategy for brain metastases in women suffering from the most common types of advanced EC.

\section{MATERIALS AND METHODS}

\section{Case reports}

We report two cases of patients with brain metastasis from EC treated in our institution.

\section{Literature review}

We conducted a systematic literature review focused on cerebral metastases from EC on Medline database (https://pubmed.ncbi.nlm.nih.gov/) from inception until December 2020. We used the advanced search mode with the following associations of Mesh terms in the 
title: (brain metastasis OR brain metastases OR cerebral metastasis OR cerebral metastases OR brain OR cerebral) AND (uterus OR endometrial).

\section{Inclusion and exclusion criteria}

All the English-language articles with individual extractable date concerning brain metastasis from EC were included in the quantitative analysis. The case series with no individual extractable data, but relevant information, were retained in the qualitative analysis. The exclusion criteria were articles not written in English, articles not directly relevant to the subject, articles reporting very rare tumoral subtypes, articles that could not be found despite being indexed in Medline, and articles without individual extractable data.

\section{Data extraction}

All the articles included in the quantitative analysis were screened in a systematic manner and the following information was extracted as previously planned: patient's age at the time of diagnostic of EC; cancer grade and FIGO stage; treatment including type of surgery, adjuvant radiotherapy, brachytherapy, and chemotherapy; average interval until brain metastasis diagnosis; neurological symptoms; location of brain metastasis, presence of other metastatic sites; treatment of brain metastasis including neurosurgery, radiosurgery, adjuvant radiotherapy or chemotherapy; interval until patient's death or alive at last followup. This work was conducted in compliance with the Preferred Reporting Items for Systematic reviews and Meta-Analyses. [12]

\section{Primary and secondary endpoints of the study}

The primary endpoint was to define the optimal treatment strategy for brain metastasis from EC. The secondary endpoint was to assess the importance of the usual major preoperative prognostic factors for brain metastases, but this time for EC (including the patient's age, the number of cerebral metastases, and the presence of extra-cerebral metastatic sites).

\section{Statistical analyses}

All statistical analyses were conducted using GraphPad Prism 8.0 (GraphPad Software Inc, San Diego, California). Categorical variables were presented as numbers and percentages, and continuous variables were presented as median and interquartile range (IQR). Median overall survival was defined as the time interval between diagnosis of brain metastasis and death from any cause and estimated using the Kaplan-Meier method. Survival rates were 
presented in percentages with their $95 \%$ confidence interval $(95 \% \mathrm{CI})$. Differences in survival depending on clinical or radiologic data (age, number of brain metastases and number of extra-cerebral metastatic sites) and on the type of treatment were assessed using the Log-rank (Mantel-Cox) test. A two-sided p-value of less than 0.05 was considered to indicate statistical significance.

\section{RESULTS}

\section{Case 1}

A 70-year-old patient was operated on by hysterectomy for endometrioid adenocarcinoma. Three years later, she presented local recurrence and benefited from total pelvectomy with healthy margins consistent with a grade 2, FIGO IVA endometrioid adenocarcinoma. The tumor was adherent to the bladder and the rectum, and there was a vaginal fistula. The patient underwent adjuvant pelvic radiotherapy and chemotherapy. Two months later, she presented amnesia and psychomotor retardation. Neuroimaging revealed a parieto-occipital lesion with a heterogeneous nodular and necrotic portion, and a deeper ring-enhanced cystic portion, responsible for a large vasogenic cerebral edema (Fig. 1). She underwent craniotomy and complete resection of this brain lesion which presented a clear cleavage plane with the adjacent cerebral parenchyma. Pathology report was consistent with a metastasis from EC. Immunohistochemical analysis showed estrogen receptors ++++, progesterone receptors,$+ \mathrm{CK} 7+$, EMA ++. She benefited from surgical site radiotherapy afterwards. The PET-scan did not reveal any extra-cerebral metastatic site. Anti-epileptic medication (levetiracetam) was stopped 6 years after brain surgery. Nine years after, she is doing well, and she is free of disease.
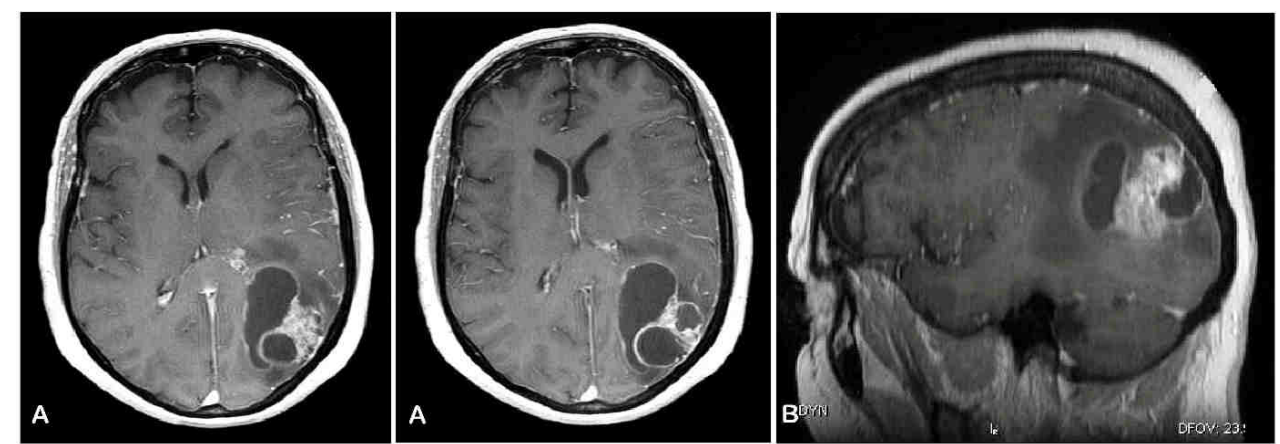

Figure 1. Post-contrast T1-weighted brain MRI shows a left parietal metastasis with a peripheral nodular portion and large deep ring-enhanced cysts in axial (A) and sagittal (B) view. 


\section{Case 2}

A right-handed 53-year-old patient was diagnosed with stage II endometrial adenocarcinoma. She was treated with radiotherapy, chemotherapy (cisplatin) and finally brachytherapy. A few months later, she was diagnosed with cervical lymph node progression and she was treated with a second-line chemotherapy (paclitaxel, carboplatin). Eight months later, subdiaphragmatic lymph nodes appeared and she was treated with a third-line chemotherapy (doxorubicine). Finally, she presented disseminated lymphatic disease (subclavicular fossa, mediastinal, para-aortic) and was treated with a fourth-line chemotherapy (gemcitabine). At this time, she developed motor dysphasia and right hemiparesis. Neuroimaging revealed a lesion in the left parietal lobe with a larger diameter of $26 \mathrm{~mm}$, facing the ventricular trigone, with heterogeneous enhancement and responsible for an important vasogenic cerebral edema (Fig. 2). She Underwent craniotomy and resection of the lesion which presented a cleavage plane with the surrounding cerebral parenchyma. The pathology report was consistent with a mildly differentiated (grade 2) endometrial metastasis. Immunohistochemical study revealed CK7+ CKK20+, CDX2+, estrogen receptor- (Fig. 3). After the surgery, the patient presented a transient parietal lobe syndrome with mild alexia and incomplete Wernicke's aphasia, and she was sent to intensive neurological rehabilitation. She benefited from postoperative stereotactic radiosurgery with cyberknife ${ }^{\mathrm{TM}}$ on the surgical cavity. After 6 months, her neurological condition improved and there was no evidence of cerebral relapse.

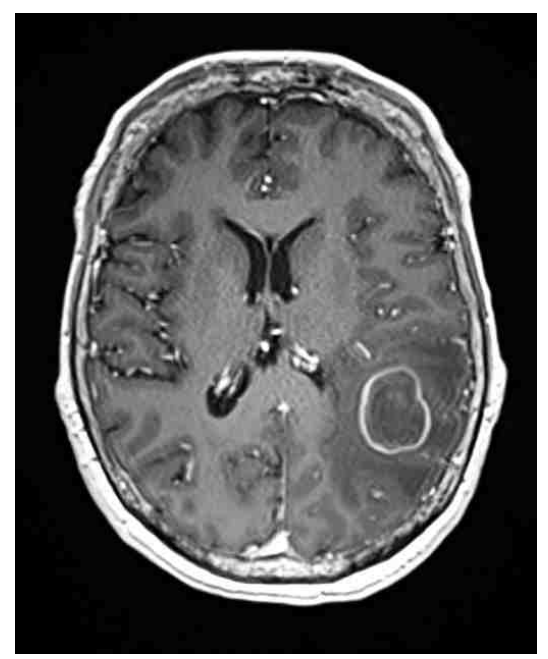

Figure 2. Post-contrast T1-weighted brain MRI shows a left parietal ring-enhanced cystic metastasis facing the ventricular trigone. 


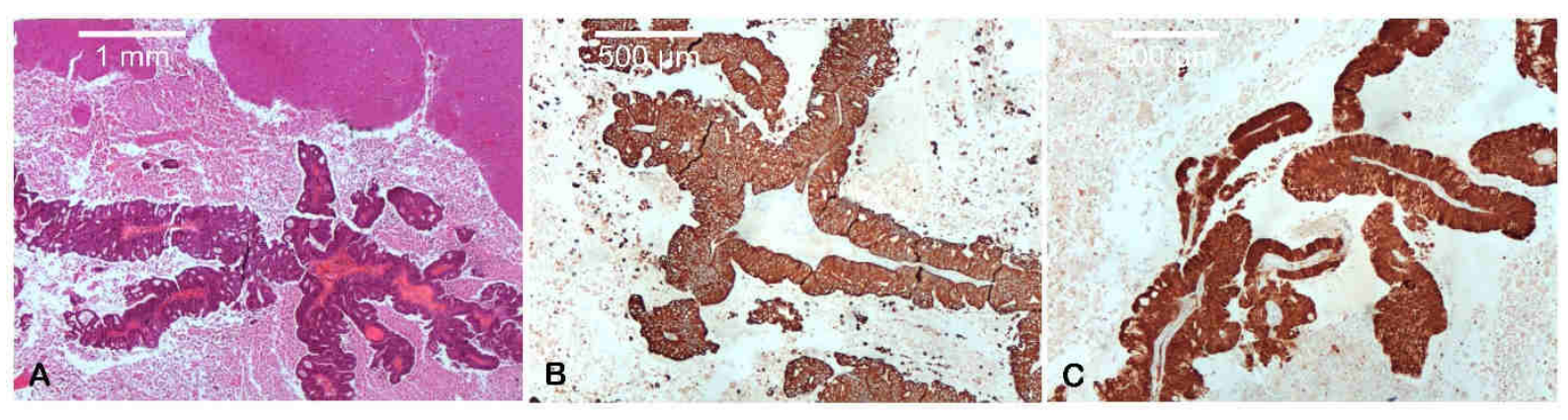

Figure 3. Pathology examination using optical microscope. (A) Adenocarcinomatous tumoral tissue (black arrowheads) within the cerebral parenchyma (white arrowhead) (2.5x magnification). Immunohistochemical examination shows expression of (B) CK7 and (C) P16 (5x magnification).

\section{LITERATURE REVIEW}

\section{Database research}

Reports concerning patient suffering from endometrial malignancy with brain metastases ranged from 1975 to 2019 [6-8,11,13-31]. The research yielded 117 articles, and 108 after exclusion of duplicated works. After the first screening, 72 articles met the exclusion criteria. Among the 36 articles retained, eight articles also met the exclusion criteria after full reading of the content. Among the 28 articles included in the qualitative analysis, 23 articles with extractable individual data (18 case reports -up to 3 patients- and 5 case series) were included in the quantitative analysis. PRISMA flow diagram is provided in Fig. 4. Patients' characteristics, demographics and clinical presentation A total of 87 patients were included in this series. 

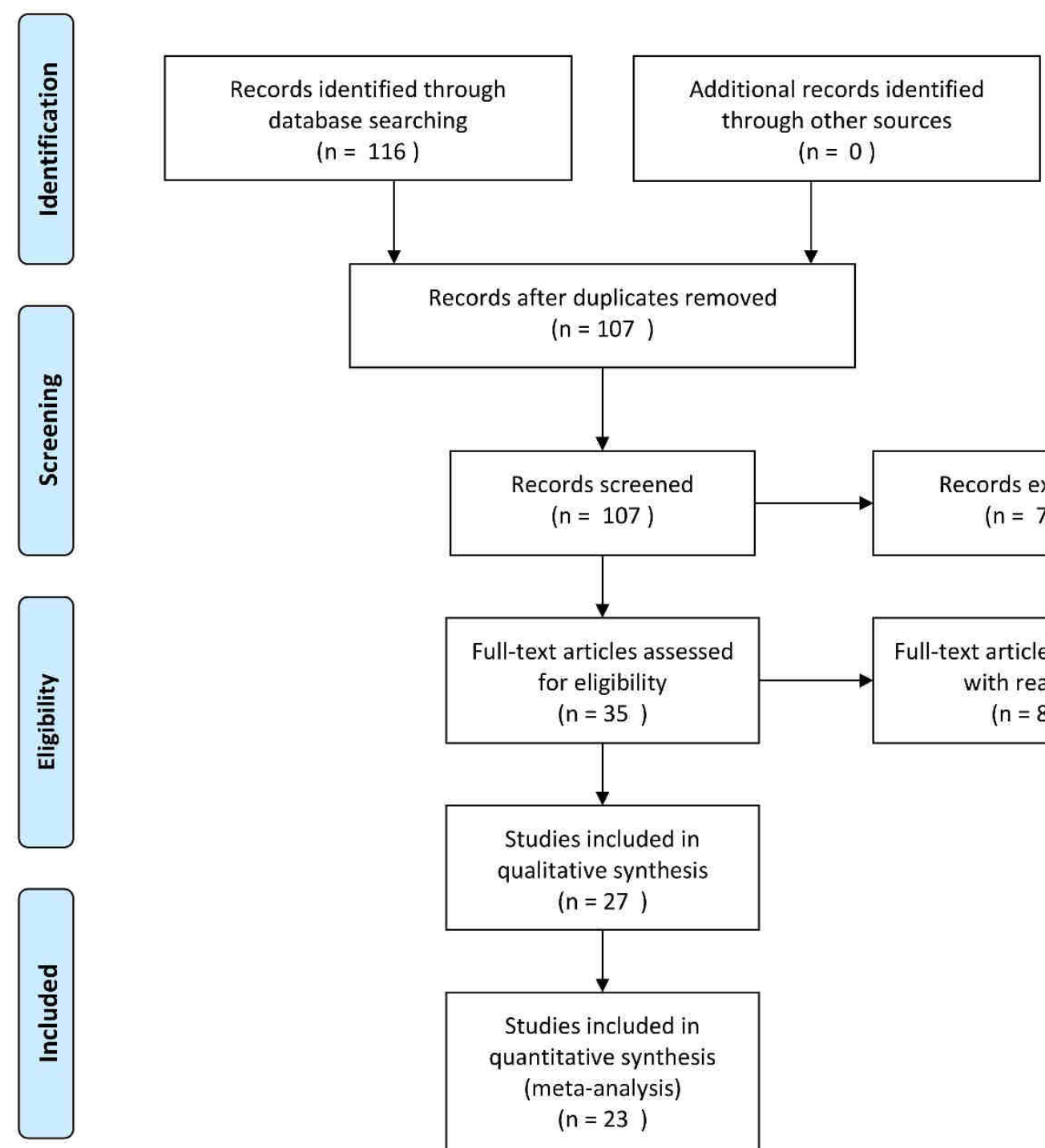

(n) duplicates removed $(n=107)$
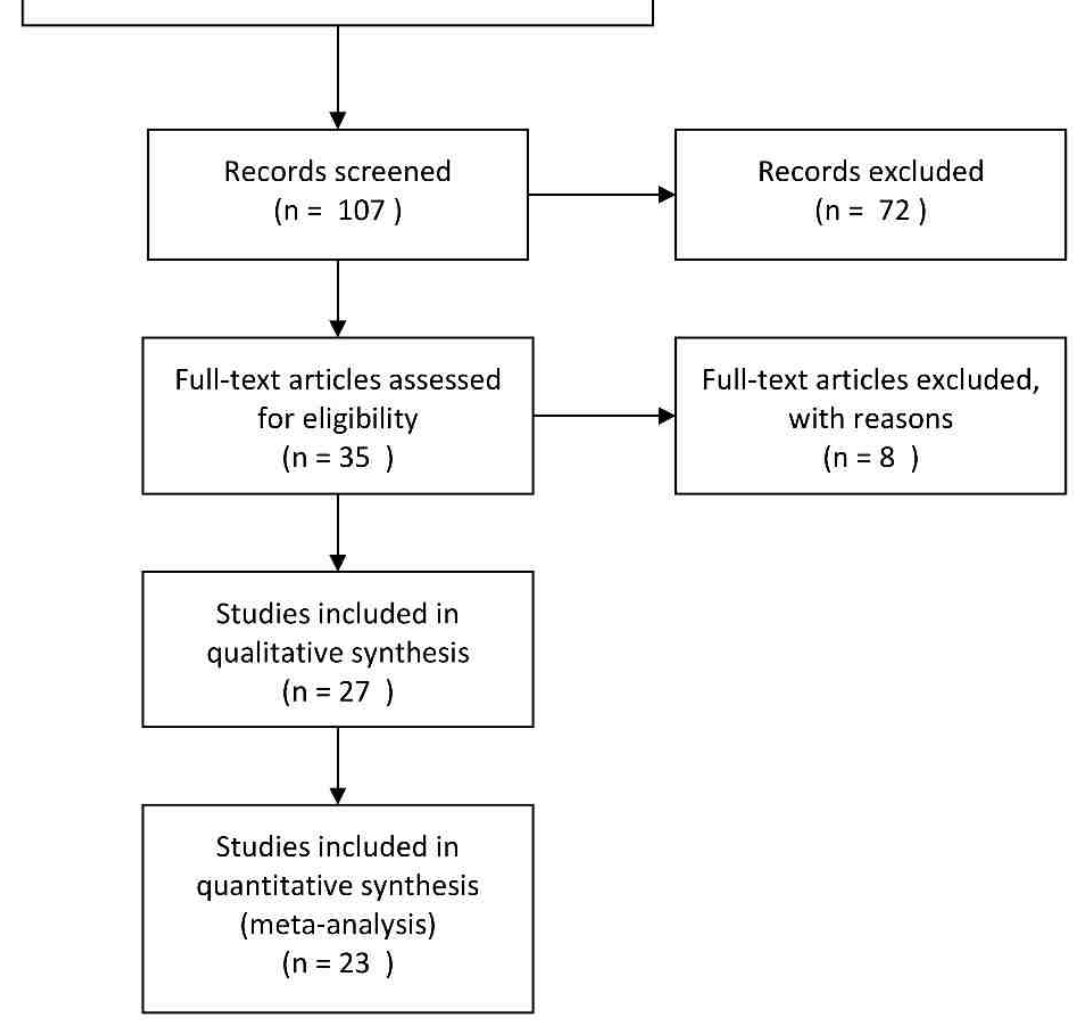

From: Moher D, Liberati A, Tetzlaff J, Altman DG, The PRISMA Group (2009). Preferred Reporting Atems for Systematic Reviews and MetaAnalyses: The PRISMA Statement. PLoS Med 6(7): e1000097. doi:10.1371/journal.pmed1000097

\section{For more information, visit www.prisma-statement.org.}

Figure 4. PRISMA flowchart for systematic review on Medline database focused on brain metastases from endometrial cancer. 
The mean age of the patients at the time of diagnosis of endometrial malignancy was 59 $( \pm 11)$ years old. EC was most of the time revealed by post-menopause abnormal uterine bleeding. The most frequent subtype of cancer was endometrial adenocarcinoma (84\%, $n$ $=73)$ followed by serous carcinoma $(4.6 \%, \mathrm{n}=4)$, clear cell carcinoma $(4.6 \%, \mathrm{n}=4)$ and rarely mixed müllerian tumor. Half of the tumors were classified as grade $3(54 \%, n=47)$ and one-sixth as grade $2(15 \%, \mathrm{n}=13)$. Half of the patients suffered from an advancedstage disease ranked as FIGO III or IV $(55 \%, \mathrm{n}=48)$. The patients' complete clinical data are provided in Table 3.

\begin{tabular}{|c|c|}
\hline Characteristics & $\begin{array}{c}\text { Number of patients } \\
\text { (percentage) / mean } \\
\text { value }\end{array}$ \\
\hline Number of patients included & 87 \\
\hline $\begin{array}{l}\text { Mean age at endometrial cancer diagnosis } \\
\leq 60 \text { year-old }\end{array}$ & $\begin{array}{c}59 \pm 11 \\
46(52.9 \%)\end{array}$ \\
\hline Brain met operated on & $24(52.2 \%)$ \\
\hline$>60$ year-old & $41(47.1 \%)$ \\
\hline Brain met operated on & $18(43.9 \%)$ \\
\hline \multicolumn{2}{|l|}{ Subtypes of cancer } \\
\hline adenocarcinoma & $73(83.9 \%)$ \\
\hline serous carcinoma & $4(4.6 \%)$ \\
\hline clear cell carcinoma & $4(4.6 \%)$ \\
\hline Other subtypes & $6(6.9 \%)$ \\
\hline \multicolumn{2}{|l|}{ Tumor grade } \\
\hline 1 & $5(5.7 \%)$ \\
\hline 2 & $13(14.9 \%)$ \\
\hline 3 & $47(54 \%)$ \\
\hline \multicolumn{2}{|l|}{ Cancer stage } \\
\hline I & $23(26.4 \%)$ \\
\hline II & $7(8 \%)$ \\
\hline III & $30(34.5 \%)$ \\
\hline IV & $18(20.7 \%)$ \\
\hline Hysterectomy & $78(89.7 \%)$ \\
\hline plus radiotherapy and chemotherapy & $24(30.8 \%)$ \\
\hline plus radiotherapy & $21(27 \%)$ \\
\hline plus chemotherapy & $6(7.7 \%)$ \\
\hline No hysterectomy in prevalent brain mets & $3(3.3 \%)$ \\
\hline
\end{tabular}

Table 1 part 1. Patients' characteristics: endometrial cancer

\section{Treatment of endometrial cancer}

Total hysterectomy and bilateral adnexectomy was performed in $90 \%$ of the patients $(\mathrm{n}=$ 78/87). Although systematic pelvic lymphadenectomy with or without para-aortic lymphadenectomy is the standard surgical treatment in non-stage I FIGO EC, it was explicitly reported in only $18 \%$ of the patients who were operated on (14/78). Postoperative adjuvant therapy consisted in radiotherapy plus chemotherapy (18 patients), radiotherapy 
plus brachytherapy (4 patients), radiotherapy plus brachytherapy and chemotherapy (1 patient), radiotherapy alone (17 patients), and chemotherapy alone (5 patients). Three patients with brain metastasis prevalent to the diagnosis of endometrial malignancy were not operated on (Table 1.1).

\begin{tabular}{|c|c|}
\hline Characteristics & $\begin{array}{c}\text { Number of patients } \\
\text { (percentage) / mean } \\
\text { value }\end{array}$ \\
\hline \multicolumn{2}{|l|}{ Brain metastasis } \\
\hline Average time to brain metastasis (months) & $24.7( \pm 35)$ \\
\hline Average time to secondary brain metastasis & $29.3( \pm 36)$ \\
\hline Prevalent brain metastasis & $10(11.5 \%)$ \\
\hline Operated on & $6(60 \%)$ \\
\hline Concomitant brain metastasis & $3(3.4 \%)$ \\
\hline Operated on & $3(100 \%)$ \\
\hline Single & $51(58.6 \%)$ \\
\hline Operated on & $33(64.7 \%)$ \\
\hline Two & $16(17.2 \%)$ \\
\hline Operated on & $6(37.5 \%)$ \\
\hline Multiple & $20(23 \%)$ \\
\hline Operated on & $3(15 \%)$ \\
\hline Infratentorial & $22(25.3 \%)$ \\
\hline Operated on & $6(27.3 \%)$ \\
\hline \multicolumn{2}{|l|}{ Neurological symptoms } \\
\hline Focal signs & $53(60.9 \%)$ \\
\hline Hemiparesis (focal sign) & $34(64.2 \%)$ \\
\hline Intracranial hypertension (ICH) & $29(32.2 \%)$ \\
\hline Severe ICH (drowsiness) & $3(10.3 \%)$ \\
\hline Seizures & $12(13.8 \%)$ \\
\hline \multicolumn{2}{|l|}{ Other metastatic sites } \\
\hline Patients free of other metastatic site & $35(40.2 \%)$ \\
\hline Operated on & $27(77 \%)$ \\
\hline Patients with extra-cerebral metastases & $52(59.8 \%)$ \\
\hline Operated on & $15(28.9 \%)$ \\
\hline Lung & $31(35.6 \%)$ \\
\hline Peritoneum & $14(16.1 \%)$ \\
\hline Pelvis & $12(13.8 \%)$ \\
\hline Bone & $12(13.8 \%)$ \\
\hline \multicolumn{2}{|l|}{ Brain metastasis treatment } \\
\hline All craniotomies & $42(48.3 \%)$ \\
\hline Craniotomy + radiosurgery & $2(4.8 \%)$ \\
\hline Craniotomy + radiotherapy & $32(81 \%)$ \\
\hline Craniotomy alone & $8(19 \%)$ \\
\hline Radiosurgery alone & $2(2.3 \%)$ \\
\hline Radiotherapy alone & $31(35.6 \%)$ \\
\hline Palliative care & $12(13.8 \%)$ \\
\hline Mean age & 59.2 \\
\hline extreme age ( $\geq 79$ year-old) & $2(16.7 \%)$ \\
\hline Multiple brain metastases & $5(41.7 \%)$ \\
\hline Deep brain metastases & $2(16.7 \%)$ \\
\hline
\end{tabular}

Table 1 part 2. Patients' characteristics: brain metastases

\section{Clinical presentation of cerebral metastases}

The average time from EC to the diagnosis of brain metastases was $25 \pm 35$ months. Fifteen percent of the patients $(\mathrm{n}=13)$ presented with "primary" (synchronous) brain metastases; among them, $11.5 \%(\mathrm{n}=10)$ presented with a prevalent brain metastasis and three percent 
$(\mathrm{n}=3)$ with concomitant EC and brain metastasis at diagnosis. The average time between endometrial malignancy and "secondary" (metachronous) brain metastasis was $29 \pm 36$ months for the rest of the $85 \%$ of the patients $(n=74)$ in this review.

The most frequent neurological symptoms were focal signs in $61 \%$ of the patients $(n=53)$, including hemiparesis in 34 patients, symptoms of intracranial hypertension or headaches in $32 \%$ of the patients $(n=29)$, and seizures in $14 \%$ of the patients $(n=12)$. Fifty-nine percent of the patients $(n=51)$ presented a single brain metastasis, $17 \%$ of the patients $(n$ $=16)$ presented two brain metastases, and $23 \%(\mathrm{n}=20)$ presented multiple brain metastases. (Table 1.2)

\section{Treatment of cerebral metastases}

Forty eight percent of the patients $(n=42 / 87)$ benefited from a neurosurgical procedure. Eighty-one percent of them $(n=32 / 42)$ benefited from radiotherapy and five percent $(n=$ $2 / 42$ ) benefited from radiosurgery. Surgical excision (SE) was the sole treatment for $19 \%$ of the patients $(n=8 / 42)$. Radiosurgery alone was performed in two percent of the cases ( $n$ $=2 / 87)$, and radiotherapy alone was performed in $36 \%$ of the cases $(n=31 / 87)$. With regards to the number of brain metastasis, $65 \%$ of the patients $(n=33 / 51)$ with a single brain metastasis were operated on, which decreased to $38 \%(n=6 / 16)$ in case of two brain metastases, and down to $10 \%(n=3 / 20)$ in case of multiple brain metastases.

With regards to the stage of EC, $40 \%$ of the patients $(n=35)$ presented without any evidence of extra-cerebral disease and $77 \%$ of them $(n=27 / 35)$ benefited from a neurosurgical procedure. Sixty percent of the patients $(n=52)$ presented at least one extracerebral metastatic site and $29 \%$ of them $(n=15 / 52)$ were operated on.

\section{Outcome}

The median overall survival was 15 months (IQR 2-12) in this series. The patients treated with craniotomy-excision followed by radiotherapy $(\mathrm{n}=32)$ presented a median overall survival of 32 months (IQR 9-48), compared to 5.4 months (IQR 2-6) for patients treated with radiotherapy and/or chemotherapy $(\mathrm{n}=31)$, and 4.8 months (IQR 1.3125-8) for patients treated with surgery alone $(n=8)(\mathrm{p}<0.0001)$.

The patients with a single brain metastasis $(\mathrm{n}=51)$ presented a median overall survival of 21.7 months (IQR 3.25-27.25) compared to 5.8 months (IQR 1-5) for patients with at least two brain metastases $(n=36)(\mathrm{p}<0.0001)$. The patients free of extra-cerebral disease $(n=$ 
35) presented a median overall survival of 22.9 months (IQR 3.25-29.5) compared to 10 months (IQR 1-8.25) for the patients suffering from extra-cerebral metastases $(\mathrm{n}=52)(\mathrm{p}$ $=0.0011)$.

The patients aged 60 years-old or younger presented a median overall survival of 17 months (IQR 1.8125-15.75) compared to 13 months (IQR 2-9.25) for the patient older than $60(\mathrm{p}=$ 0.58). Kaplan-Meier estimate are provided in Fig. 5 and Table 2.

\begin{tabular}{|lccc|}
\hline Characteristics & $\begin{array}{c}\text { Number of } \\
\text { patients }\end{array}$ & $\begin{array}{c}\text { Average survival } \\
\text { (months) }\end{array}$ & $\begin{array}{c}\text { Statistical } \\
\text { significance }\end{array}$ \\
\hline Age & & & $\mathrm{P}=0.58$ \\
$\leq 60$ & 46 & 17.02 & \\
$>60$ & 41 & 12.54 & $\mathrm{P}<0.0001$ \\
Number of brain metastases & & & \\
1 & 51 & 21.4 & $\mathrm{P}=0.0011$ \\
$>1$ & 36 & 5.83 & \\
Number of extra-cerebral & & & \\
metastatic sites & & & $\mathrm{P}<0.0001$ \\
0 & 35 & 22.27 & \\
$\geq 1$ & 52 & 9.96 & \\
Treatment of brain metastasis & & & \\
Surgery + gammaknife & 2 & 84 & \\
Surgery + radiotherapy & 32 & 28.18 & \\
Gammaknife & 2 & 10.5 & \\
Radiotherapy & 31 & 5.02 & \\
Surgery & 8 & 4.75 & \\
Other & 12 & & \\
& & & \\
\end{tabular}

Table 2. Significant prognostic factors in patients with brain metastasis from endometrial cancer, based on the criteria from the Graded Prognostic Assessment for brain metastases. 

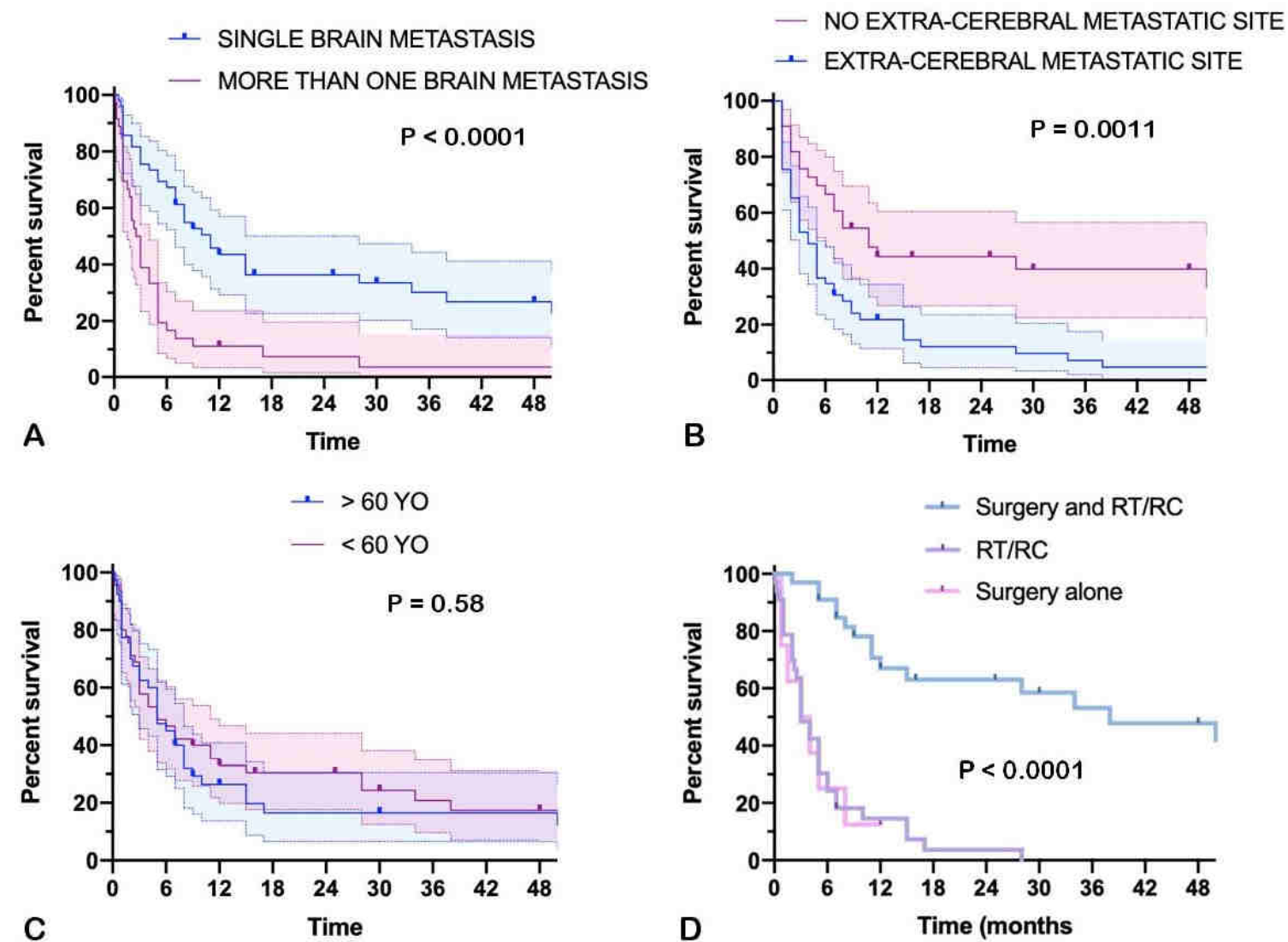

C

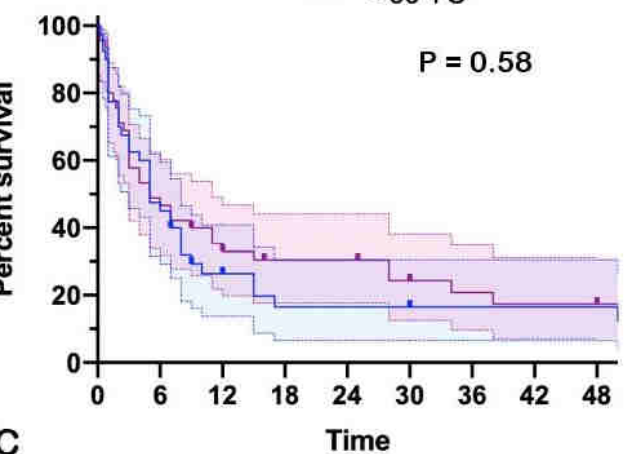

Figure 5. Kaplan-Meier estimate depending on (A) the number of cerebral metastases (one versus at least two), (B) the presence of extra-cerebral metastatic sites (none versus at least one, (C) the age of the patient (60 or less versus more than 60), and (D) the treatment of cerebral metastases (surgery plus radiotherapy versus other treatments).

\section{DISCUSSION}

\section{Previous series in the literature}

To our knowledge, there is only one other contemporary review focused on brain metastases from EC which included 98 reported cases. This research was conducted on Medline database with broader inclusion criteria, namely articles written in four different languages (English, French, Spanish and Italian) and including all the subtypes of EC. [8] To ensure some homogeneity in the present study, rare histological subtypes of EC were purposely excluded. Another contemporary monocentric retrospective case series reported the outcome of 30 patients treated for brain metastases from EC and is discussed further below. [32] 
In this review, the presence of a single brain metastasis was identified as a good prognostic factor with a median overall survival of 21.7 months ( $p<0.0001)$. In the same way, the absence of extra-cerebral metastatic sites was identified as a good prognostic factor with a median overall survival of 22.9 months $(p=0.0011)$. In our opinion, these are the two most important criteria to be taken into account to further discuss the therapeutic strategy. The treatment of cerebral metastases is exhausting for the patient, whether it is SE of stereotactic radiotherapy, and these two factors illustrate the importance of patient selection. Ideally, SE should be performed for healing purpose of the cerebral disease in patients with a manageable extra-cerebral disease. In other less encouraging situations such as large symptomatic lesions with intracranial hypertension refractory to medical treatment, or multiple lesions with no histological diagnostic, SE may be required for symptomatic and/or for diagnostic purpose. In any event, patients with cannonball brain metastases or with an advanced-stage extra-cerebral disease should not be operated on because they wouldn't even withstand the procedure. Surprisingly, an age of 60-year-old or less was not associated with a better median overall survival $(p=0.58)$.

We purposely chose to ascertain the relevance of these potential prognostic factors in the case of brain metastases from EC because they are recurrently found in the pre-operative scoring systems for brain metastases. The Graded Prognostic Assessment (GPA) score has been defined for six different types of cancers (non-small-cell and small-cell lung cancer, melanoma, breast cancer, renal cell carcinoma, and gastro-intestinal cancer) and variably includes the patient's age, the Karnofsky Performance Status (KPS), the number of cerebral metastases, the presence of extra-cerebral metastatic sites, and the subtype of cancer. $[33,34]$ It displays a strong prognostic value and it is easily applicable in a daily clinical practice. [35] The Recursive Partitioning Analysis score includes the patient's age, the KPS, and the presence of extra-cerebral metastatic sites. [36]. Unfortunately, we could not determine the KPS of the patients in our series because of incomplete clinical data.

\section{Surgical considerations}

Most of the time, there is a difference of consistency between the metastasis and the surrounding brain parenchyma and, even though there is not a real capsule, a cleavage plane can be found making "en-bloc" excision feasible. This must be nuanced in cystic metastases where a breach in the cyst's wall may result in the emptying of the content and the collapsing of the tumor, making complete excision tricky. To ensure complete SE, the 
surgeon may perform a supra-total excision by removing a thin strip of adjacent parenchyma, or he can refill the metastatic cyst with fibrin glue to pursue the dissection. [37] In our institution, we faced two authentic cystic metastases from EC (Fig. 1 and 2). Nevertheless, only two other cases of cystic metastases were clearly reported in this review. $[20,24]$

\section{Therapeutic strategy for brain metastasis}

In this review, SE followed by radiotherapy provided a better median overall survival than radiotherapy and/or chemotherapy, or surgery alone (respectively 28 months versus 5.2 or $4.8, \mathrm{p}<0.0001$ ). Since the 1990s, SE followed by whole brain radiotherapy (WBRT) has proven its benefits for the treatment of a single brain metastasis. [38,39] However, recent advances in targeted therapies have improved the prognosis of cancer patients. Consequently, the neurosurgeon and the radiation therapist now also face the need of preserving the patient's higher cerebral functions. In this context, stereotactic radiosurgery (SRS) has become a valuable therapeutic option in case of metastasis measuring less than $3 \mathrm{~cm}$, or in case of multiple small cerebral metastases. [40] The efficiency of SRS is comparable to SE in such case, even for radioresistant brain metastases. [41,42] SRS has also become a possible therapeutic option for cystic metastases. [43] Finally, SRS can be used for the irradiation of the surgical site after SE of a brain metastasis. [44] Thus, SE and SRS can be seen as two useful therapeutic options for patients suffering from brain metastases. [45,46] The former provides immediate mass effect relief for symptomatic large or cystic brain metastases, while the latter provides a less-invasive long-term control over one or multiple smaller lesions. These options must nowadays be preferred in order to defer the neurocognitive impairment induced by WBRT for patients who present longer life expectancy. [47]

Unfortunately, we could not determine the type of radiation therapy received by some of the patients in this review because of a lack of data. Thirty-eight percent of the patients (n $=33 / 87)$ benefited from WBRT, five percent of the patients $(n=4 / 87)$ benefited from SRS, and $34 \%$ of the patients $(n=30 / 87)$ benefited from radiotherapy of unknown nature. Patients treated with SE followed by SRS $(n=2)$ seemed to present the longest median overall survival (84 months), followed by SE plus radiotherapy ( $\mathrm{n}=32,32.4$ months), radiotherapy and / or chemotherapy $(n=43,5.3$ months) and finally SE alone $(n=8,4.8$ months); nevertheless, these results cannot be generalized. 
Naturally, the patients with a single brain metastasis and those with no extra-cerebral metastatic sites seemed more likely to benefit from a neurosurgical procedure than the others (65\% vs $38 \%$ and $77 \%$ vs $29 \%$, respectively). It was therefore difficult to ascertain if the positive outcome in the SE plus radiotherapy group was due to the preoperative selection of the patients, the impact of an aggressive surgical strategy, or the possible indolence of the tumor.

Lastly, SE is required in case of etiologic doubt. This is particularly relevant in patients with history of EC because the occurrence of brain metastases is an exceptional event in the natural course of the disease. This can be a supplementary argument toward SE for diagnostic purpose in the case of EC.

Bhambhvani et al. presented a monocentric retrospective series of 30 patients treated for brain metastases from EC. [32] All histological subtypes were included. Mean age was 62year-old and $80 \%$ of the patients were diagnosed with FIGO stage III tumors, which is surprisingly more aggressive than the findings in our review. The average time until the diagnosis of brain metastases was 20.8 months. The median overall survival was 6.8 months. Patients treated with SE and SRS $(n=11 / 30,37 \%)$ presented a median overall survival of 15.7 months compared to 5.6 months for patients treated with SRS alone $(\mathrm{n}=$ 17/30, 57\%). These results significantly differ from our findings and may be in part explained by the aggressive character of the tumors in the authors' series.

\section{Retrospective analysis of our cases in the light of this review}

The two patients treated in our institution benefited from SE of a single symptomatic brain metastasis and postoperative SRS of the surgical cavity. The first-one was 70 years-old with a single symptomatic brain lesion and was free of extra-cerebral disease. The secondone was 53 years-old with a single symptomatic brain lesion and a slowly progressive disease. In both cases, the SE was performed after multidisciplinary team meeting in the setting of a personalized cancer treatment plan. The long survival of the first patient (nine years) and the good recovery of the second patient let us think that they both met wise inclusion criteria for the SE of the brain metastasis.

\section{Limitations}

This work presents some limits inherent to its retrospective nature. Case reports unconsciously select patients with favourable outcome; thus, the compilation of such 
articles may lead to a reporting bias which underestimates the mortality rate. What is more, there is an attrition bias due to the loss of information between the medical file of the patient, the reporting of the case by the sole author and then our own collect of information for this review. There was a lack of data concerning the treatment of EC in some of the case series, as well as for the management of cerebral metastases. Besides, a few works were carried out before SRS was available as an effective treatment for small size metastases. Because of the small size of our series, we could not distinguish all the treatment options in the statistical analysis.

\section{CONCLUSION}

In the light of this review, patients with history of EC who are suffering from a single brain lesion with a controlled systemic disease could benefit from the SE of the lesion for diagnostic purpose, symptomatic relief and as part of the treatment. After confirmation of the diagnosis of cerebral metastasis, the patient should benefit from stereotactic radiotherapy of the surgical site. The neurosurgical indication should be part of a multidisciplinary team meeting; its goal remains the cerebral control of the disease which requires medical treatment afterwards. The Graded Prognostic Assessment (GPA) score provides a simple and reliable tool reflecting the most important factors for whether to perform surgery for brain metastases: it is a score adapted for the six most frequent types of cerebral metastases. Our work could help to adapt the GPA score for brain metastasis in EC. Multicentric prospective trials are required to validate these data. 


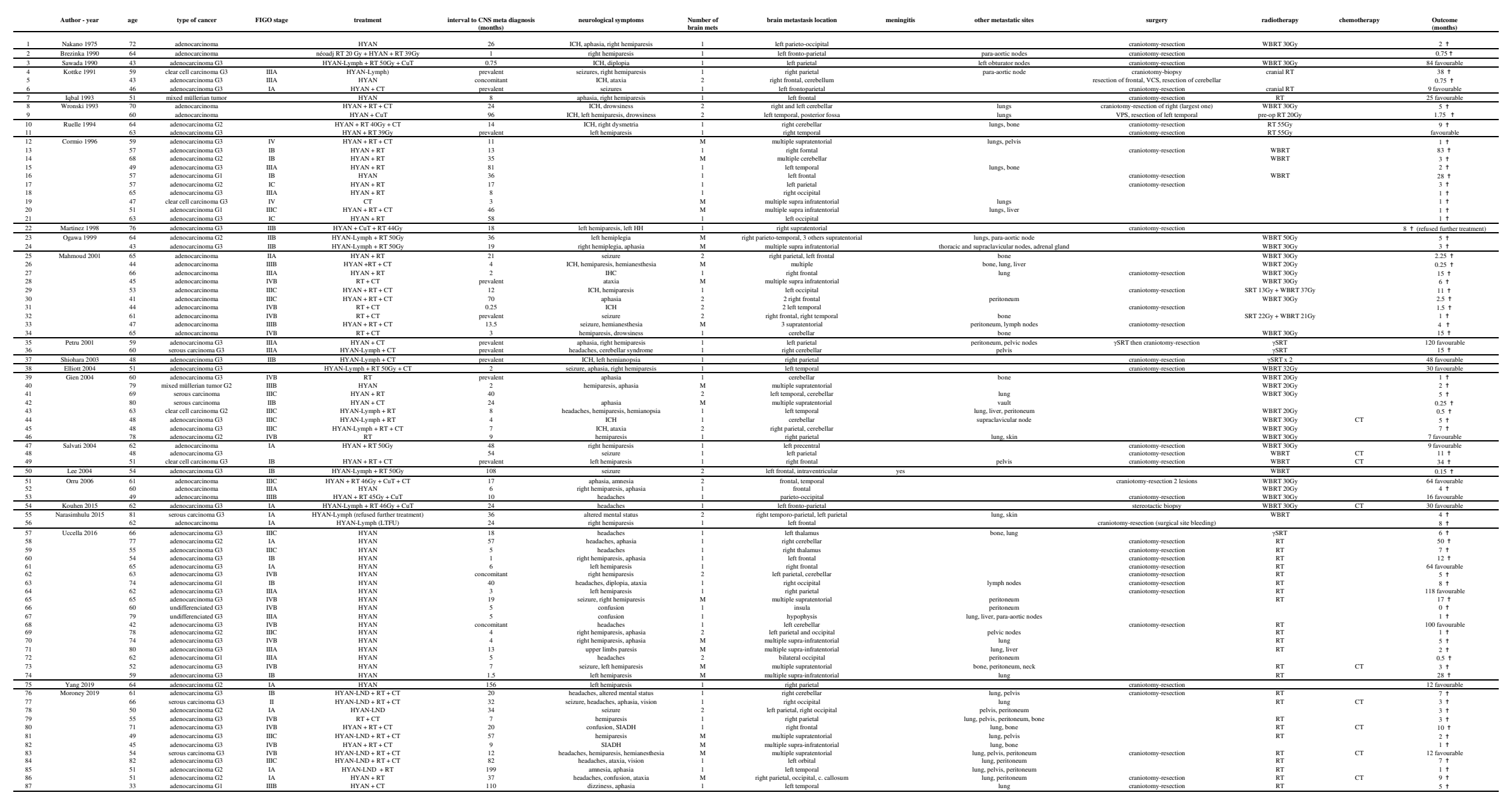

Table 3. Systematic literature review (Medline) focused on brain metastases from endometrial cancer: patients' complete data 


\section{REFERENCES}

[1] P. Morice, A. Leary, C. Creutzberg, N. Abu-Rustum, E. Darai, Endometrial cancer, The Lancet. 387 (2016) 1094-1108. https://doi.org/10.1016/S0140-6736(15)00130-0.

[2] R.L. Siegel, K.D. Miller, A. Jemal, Cancer statistics, 2015: Cancer Statistics, 2015, CA: A Cancer Journal for Clinicians. 65 (2015) 5-29. https://doi.org/10.3322/caac.21254.

[3] N. Colombo, E. Preti, F. Landoni, S. Carinelli, A. Colombo, C. Marini, C. Sessa, Endometrial cancer: ESMO Clinical Practice Guidelines for diagnosis, treatment and follow-up, Annals of Oncology. $24 \quad$ (2013) vi33-vi38. https://doi.org/10.1093/annonc/mdt353.

[4] J. Ferlay, I. Soerjomataram, R. Dikshit, S. Eser, C. Mathers, M. Rebelo, D.M. Parkin, D. Forman, F. Bray, Cancer incidence and mortality worldwide: Sources, methods and major patterns in GLOBOCAN 2012: Globocan 2012, International Journal of Cancer. 136 (2015) E359-E386. https://doi.org/10.1002/ijc.29210.

[5] S. Pecorelli, Revised FIGO staging for carcinoma of the vulva, cervix, and endometrium,

International Journal of Gynecology \& Obstetrics. $105 \quad$ (2009) 103-104. https://doi.org/10.1016/j.ijgo.2009.02.012.

[6] G. Cormio, A. Lissoni, G. Losa, G. Zanetta, A. Pellegrino, C. Mangioni, Brain Metastases from Endometrial Carcinoma, Gynecologic Oncology. 61 (1996) 40-43.

https://doi.org/10.1006/gyno.1996.0093.

[7] L. Gien, J. Kwon, D. Dsouza, J. Radwan, J. Hammond, A. Sugimoto, M. Carey, Brain metastases from endometrial carcinoma: a retrospective study, Gynecologic Oncology. 93 (2004) 524-528. https://doi.org/10.1016/j.ygyno.2004.02.006.

[8] S. Uccella, J.M. Morris, F. Multinu, W.A. Cliby, K.C. Podratz, B.S. Gostout, S.C. Dowdy, F. Ghezzi, P.B. Makdisi, G.L. Keeney, M.J. Link, A. Mariani, Primary brain metastases of endometrial cancer: A report of 18 cases and review of the literature, Gynecologic Oncology. 142 (2016) 70-75. https://doi.org/10.1016/j.ygyno.2016.04.013.

[9] J.G. Aalders, V. Abeler, P. Kolstad, Recurrent adenocarcinoma of the endometrium: A clinical and histopathological study of 379 patients, Gynecologic Oncology. 17 (1984) 85103. https://doi.org/10.1016/0090-8258(84)90063-5.

[10] A.S. Achrol, R.C. Rennert, C. Anders, R. Soffietti, M.S. Ahluwalia, L. Nayak, S. Peters, N.D. Arvold, G.R. Harsh, P.S. Steeg, S.D. Chang, Brain metastases, Nature Reviews Disease Primers. 5 (2019). https://doi.org/10.1038/s41572-018-0055-y.

[11] E. Petru, S. Lax, S. Kurschel, F. Gücer, B. Sutter, Long-term survival in a patient with brain metastases preceding the diagnosis of endometrial cancer: Report of two cases and review of the literature, Journal of Neurosurgery. 94 (2001) 846-848. https://doi.org/10.3171/jns.2001.94.5.0846. 
[12] D. Moher, A. Liberati, J. Tetzlaff, D.G. Altman, The PRISMA Group, Preferred Reporting Items for Systematic Reviews and Meta-Analyses: The PRISMA Statement, PLoS Medicine. 6 (2009) e1000097. https://doi.org/10.1371/journal.pmed.1000097.

[13] K.K. Nakano, W.C. Schoene, Endometrial carcinoma with a predominant clear-cell pattern with metastases to the adrenal, posterior mediastinum, and brain, American Journal of Obstetrics and Gynecology. 122 (1975) 529-530. https://doi.org/10.1016/S00029378(16)33550-5.

[14] Ch. Brezinka, F. Fend, O. Huter, A. Plattner, Cerebral metastasis of endometrial carcinoma, Gynecologic Oncology. 38 (1990) 278-281. https://doi.org/10.1016/00908258(90)90055-P.

[15] M. Sawada, M. Inagaki, M. Ozaki, M. Yamasaki, H. Nakagawa, T. Inoue, N. Terada, A. Wada, Long-term survival after brain metastasis from endometrial cancer, Jpn. J. Clin. Oncol. 20 (1990) 312-315.

[16] K. Kottke-Marchant, M.L. Estes, C. Nunez, Early brain metastases in endometrial carcinoma, Gynecologic Oncology. 41 (1991) 67-73. https://doi.org/10.1016/00908258(91)90257-6.

[17] J.B. Iqbal, J.W. Ironside, Cerebral metastasis from a malignant mixed Müllerian tumour of the uterus, Histopathology. 23 (1993) 277-279. https://doi.org/10.1111/j.13652559.1993.tb01202.x.

[18] M. Wroński, M. Zakowski, E. Arbit, W.J. Hoskins, J.H. Galicich, Endometrial cancer metastasis to brain: Report of two cases and a review of the literature, Surgical Neurology. 39 (1993) 355-359. https://doi.org/10.1016/0090-3019(93)90199-B.

[19] A. Ruelle, M. Zuccarello, G. Andrioli, Brain metastasis from endometrial carcinoma. Report of two cases, Neurosurgical Review. 17 (1994) 83-87. https://doi.org/10.1007/BF00309993.

[20] R.M. Martı́ ez-Mañas, M. Brell, J. Rumià, E. Ferrer, Brain Metastases in Endometrial Carcinoma, Gynecologic Oncology. $70 \quad$ (1998) 282-284. https://doi.org/10.1006/gyno.1998.5021.

[21] K. Ogawa, T. Toita, Y. Kakinohana, M. Kamata, H. Moromizato, Y. Nagai, M. Higashi, K. Kanazawa, Y. Yoshii, Palliative Radiation Therapy for Brain Metastases from Endometrial Carcinoma: Report of Two Cases, Japanese Journal of Clinical Oncology. 29 (1999) 498-503.

https://doi.org/10.1093/jjco/29.10.498.

[22] A.S. Mahmoud-Ahmed, J.H. Suh, G.H. Barnett, K.D. Webster, J.L. Belinson, A.W. Kennedy, The Effect of Radiation Therapy on Brain Metastases from Endometrial Carcinoma: A Retrospective Study, Gynecologic Oncology. 83 (2001) 305-309. https://doi.org/10.1006/gyno.2001.6384. 
[23] s. shiohara, m. ohara, k. itoh, t. shiozawa, i. konishi, Successful treatment with stereotactic radiosurgery for brain metastases of endometrial carcinoma: A case report and review of the literature, International Journal of Gynecological Cancer. 13 (2003) 71-76.

https://doi.org/10.1046/j.1525-1438.2003.13017.x.

[24] K.S. Elliott, M.E. Borowsky, Y.-C. Lee, C. Rao, O. Abulafia, Prolonged survival in recurrent endometrial carcinoma to the brain, Gynecologic Oncology. 95 (2004) 247-251. https://doi.org/10.1016/j.ygyno.2004.07.030.

[25] M. Salvati, E. Caroli, E. Ramundo Orlando, A. Nardone, A. Frati, G. Innocenzi, F. Giangaspero, Solitary Brain Metastases from Uterus Carcinoma: Report of Three Cases, Journal of Neuro-Oncology. $66 \quad$ (2004) 175-178. https://doi.org/10.1023/B:NEON.0000013470.29733.62.

[26] W.-J. Lee, C.-H. Chen, S.-N. Chow, Brain metastases from early stage endometrial carcinoma 8 years after primary treatment: case report and review of the literature, Acta Obstetricia et Gynecologica Scandinavica. $85 \quad$ (2006) 890-891. https://doi.org/10.1080/00016340600616983.

[27] S. Orrù, G. Lay, M. Dessì, R. Murtas, M.A. Deidda, M. Amichetti, Brain Metastases from Endometrial Carcinoma: Report of Three Cases and Review of the Literature, Tumori Journal. 93 (2007) 112-117. https://doi.org/10.1177/030089160709300122.

[28] F. Kouhen, M. Afif, M.E. kabous, F. Raiss, N. Benhmidou, S. Majjaoui, H. Elkacemi, T. Kebdani, N. Benjaafar, Métastase cérébrale d'un cancer de l'endomètre: à propos d'un cas et une revue de la littérature, Pan African Medical Journal. 20 (2015). https://doi.org/10.11604/pamj.2015.20.68.6097.

[29] D.M. Narasimhulu, N. Khulpateea, K. Meritz, Y. Xu, Brain metastasis in two patients with stage IA papillary serous carcinoma of the uterus, Gynecologic Oncology Reports. 13 (2015) 1-4. https://doi.org/10.1016/j.gore.2015.04.002.

[30] F. Yang, Y. Shao, H. Duan, H. Xu, J. Chen, Brain metastasis from early stage endometrial carcinoma 13 years after primary treatment: a case report and review of the literature, Int J Clin Exp Pathol. 12 (2019) 1806-1810.

[31] M.R. Moroney, L.J. Wheeler, B.R. Corr, Clinical presentation of brain metastases from endometrial carcinoma: A case series, Gynecologic Oncology Reports. 28 (2019) 79-83.

https://doi.org/10.1016/j.gore.2019.03.004.

[32] H.P. Bhambhvani, O. Zhou, C. Cattle, R. Taiwo, E. Diver, M.H. Gephart, Brain Metastases from Endometrial Cancer: Clinical Characteristics, Outcomes, and Review of the Literature, World Neurosurgery. (2020) S1878875020324621. https://doi.org/10.1016/j.wneu.2020.11.087.

[33] P.W. Sperduto, N. Kased, D. Roberge, Z. Xu, R. Shanley, X. Luo, P.K. Sneed, S.T. Chao, R.J. Weil, J. Suh, A. Bhatt, A.W. Jensen, P.D. Brown, H.A. Shih, J. Kirkpatrick, L.E. Gaspar, J.B. Fiveash, V. Chiang, J.P.S. Knisely, C.M. Sperduto, N. Lin, M. Mehta, Summary Report on the Graded Prognostic Assessment: An Accurate and Facile 
Diagnosis-Specific Tool to Estimate Survival for Patients With Brain Metastases, Journal of Clinical Oncology. 30 (2012) 419-425. https://doi.org/10.1200/JCO.2011.38.0527.

[34] D.A. Karnofsky, W.H. Abelmann, L.F. Craver, J.H. Burchenal, The use of the nitrogen mustards in the palliative treatment of carcinoma. With particular reference to bronchogenic carcinoma, Cancer. 1 (1948) 634-656. https://doi.org/10.1002/10970142(194811)1:4<634::AIDCNCR2820010410>3.0.CO;2-L.

[35] G.A. Viani, L.G. Bernardes da Silva, E.J. Stefano, Prognostic Indexes for Brain Metastases: Which Is the Most Powerful?, International Journal of Radiation Oncology*Biology*Physics. $83 \quad$ (2012) $\quad 8325-\mathrm{e} 330$. https://doi.org/10.1016/j.ijrobp.2011.12.082.

[36] L. Gaspar, C. Scott, M. Rotman, S. Asbell, T. Phillips, T. Wasserman, W.G. McKenna, R. Byhardt, Recursive partitioning analysis (RPA) of prognostic factors in three radiation therapy oncology group (RTOG) brain metastases trials, International Journal of Radiation

Oncology*Biology*Physics. $37 \quad$ (1997) 745-751. https://doi.org/10.1016/S03603016(96)00619-0.

[37] T. Okuda, M. Fujita, H. Yoshioka, T. Tasaki, A. Kato, Novel surgical technique to solidify cysttype metastatic brain tumors using autologous fibrin glue for complete resection, Surgical Neurology International. 5 (2014) 100. https://doi.org/10.4103/21527806.135304 .

[38] R.A. Patchell, P.A. Tibbs, W.F. Regine, R.J. Dempsey, M. Mohiuddin, R.J. Kryscio, W.R. Markesbery, K.A. Foon, B. Young, Postoperative Radiotherapy in the Treatment of Single Metastases to the Brain: A Randomized Trial, JAMA. 280 (1998). https://doi.org/10.1001/jama.280.17.1485.

[39] R.A. Patchell, P.A. Tibbs, J.W. Walsh, R.J. Dempsey, Y. Maruyama, R.J. Kryscio, W.R.

Markesbery, J.S. Macdonald, B. Young, A Randomized Trial of Surgery in the Treatment of Single Metastases to the Brain, New England Journal of Medicine. 322 (1990) 494-500. https://doi.org/10.1056/NEJM199002223220802.

[40] D.W. Andrews, C.B. Scott, P.W. Sperduto, A.E. Flanders, L.E. Gaspar, M.C. Schell, M. Werner- Wasik, W. Demas, J. Ryu, J.-P. Bahary, L. Souhami, M. Rotman, M.P. Mehta, W.J. Curran, Whole brain radiation therapy with or without stereotactic radiosurgery boost for patients with one to three brain metastases: phase III results of the RTOG 9508 randomised trial, The Lancet. 363 (2004) 1665-1672. https://doi.org/10.1016/S01406736(04)16250-8.

[41] D. Rades, J.-D. Kueter, T. Meyners, A. Pluemer, T. Veninga, J. Gliemroth, S.E. Schild, Single brain metastasis: Resection followed by whole-brain irradiation and a boost to the metastatic site compared to whole-brain irradiation plus radiosurgery, Clinical Neurology and Neurosurgery. 114 (2012) 326-330. https://doi.org/10.1016/j.clineuro.2011.10.042. 
[42] H. Kim, T.-Y. Jung, I.-Y. Kim, S. Jung, K.-S. Moon, S.-J. Park, The Usefulness of Stereotactic Radiosurgery for Radioresistant Brain Metastases, Journal of Korean Neurosurgical Society. 54 (2013) 107. https://doi.org/10.3340/jkns.2013.54.2.107.

[43] R.H. Brigell, D.N. Cagney, A.M. Martin, L.A. Besse, P.J. Catalano, E.Q. Lee, P.Y. Wen, P.D. Brown, J.G. Phillips, I.M. Pashtan, S.K. Tanguturi, D.A. Haas-Kogan, B.M. Alexander, A.A. Aizer, Local control after brain-directed radiation in patients with cystic versus solid brain metastases, J Neurooncol. $142 \quad$ (2019) 355-363. https://doi.org/10.1007/s11060-019-03106-1.

[44] G. Minniti, V. Esposito, E. Clarke, C. Scaringi, G. Lanzetta, M. Salvati, A. Raco, A. Bozzao, R. Maurizi Enrici, Multidose Stereotactic Radiosurgery $(9 \mathrm{~Gy} \times 3)$ of the Postoperative Resection Cavity for Treatment of Large Brain Metastases, International Journal of Radiation Oncology*Biology*Physics. $86 \quad$ (2013) 623-629. https://doi.org/10.1016/j.ijrobp.2013.03.037.

[45] P. Metellus, E. Bialecki, E. Le Rhun, F. Dhermain, Neurosurgical and radiosurgical decision making in brain metastasis patients in the area of targeted therapies?, Chin Clin Oncol. 4 (2015) 19. https://doi.org/10.3978/j.issn.2304-3865.2015.06.02.

[46] E. Le Rhun, et al., Métastases cérébrales de l'adulte, ANOCEF. (2018).

[47] E.L. Chang, J.S. Wefel, K.R. Hess, P.K. Allen, F.F. Lang, D.G. Kornguth, R.B. Arbuckle, J.M. Swint, A.S. Shiu, M.H. Maor, C.A. Meyers, Neurocognition in patients with brain metastases treated with radiosurgery or radiosurgery plus whole-brain irradiation: a randomised controlled trial, The Lancet Oncology. 10 (2009) 1037-1044. https://doi.org/10.1016/S1470-2045(09)70263-3. 


\section{COMPETING INTERESTS}

N BEUCLER did not receive any funding for this work, and has no conflict of interest to disclose

A SELLIER did not receive any funding for this work, and has no conflict of interest to disclose

C BERNARD did not receive any funding for this work, and has no conflict of interest to disclose

C JOUBERT did not receive any funding for this work, and has no conflict of interest to disclose

N DESSE did not receive any funding for this work, and has no conflict of interest to disclose

A DAGAIN did not receive any funding for this work, and has no conflict of interest to Disclose 


\section{ETHICAL APPROVAL}

Informed written consent, or oral approval by phone call, was obtained from the patients whose case report are included in the manuscript. They have been given the opportunity to review the manuscript and the attached files, or they have been given a precise description of these contents. This work was conducted in accordance with the Declaration of Helsinki 1964 or its further amendments. For retrospective reviews, the formal approval of an academic or hospital ethical board is not required. 


\section{ACKNOWLEDGEMENTS}

We thank Dr Jean-Pierre TERRIER for his expertise in the pathology examination of the surgical samples 